\title{
LA CRÍTICA DE PEDRO ABELARDO A OTROS NOMINALISMOS
}

\author{
M. J. García-Encinas \\ Universidad de Granada
}

\begin{abstract}
RESUMEN
$\mathrm{Al}$ escribir este artículo intento recuperar, para la discusión más contemporánea sobre los universales, al menos una parte de las ideas del lógico y filósofo medieval Pedro Abelardo. En particular, hay ciertas formas de nominalismo, léase, el mentalismo, el nominalismo de conjuntos, y el nominalismo de semejanza(s), que han reaparecido con fuerza nueva en metafísica analítica contemporánea. Abelardo, como nominalista que fue, no sólo argumentó contra tesis de corte realista, sino que también evaluó y criticó otras formas de nominalismo diferentes a la suya y, en concreto, las mencionadas. Mi objeto principal es confrontar los argumentos de Abelardo con ellas, mostrando cómo sus argumentos aún prevalecen.
\end{abstract}

Palabras clave: Pedro Abelardo, nominalismo, imágenes mentales, conjuntos, semejanza.

\section{ABSTRACT}

In writing this paper it is my purpose to recover, for the most contemporary discussion on universals, a part at least of the ideas of the medieval logician and philosopher Peter Abelard. More precisely, there are certain forms of nominalism, namely, mentalism, nominalism of sets, and nominalism of simmilarity(ies), that have recently reappeared with new strength in contemporary Analytic Metaphysics. Abelard, as a nominalist, did not only argued against realist philosophies, but he also evaluated and criticized other forms of nominalims different from his own, like the ones I have just mentioned. My main object here is to confront Abelard's arguments against them, showing how his arguments still prevail.

Key words: Peter Abelard, nominalism, mental images, sets, similarity.

\section{INTRODUCCIÓN}

Clasificamos bajo lo mismo a muchos y distintos. Decimos que esto y aquello son piedras, que Platón fue discípulo de Sócrates y Aristóteles de Platón, o que la guerra y el maltrato son perniciosos. Ante estas formas, las más básicas, de referimos al mundo y a lo que en él sucede surge ya la pregunta por los universales. ¿Existen, como entidades universales, la Piedra, la Maldad, la Guerra, el Maltrato o la relación Ser-discípulo-de? Aparentemente necesarios para hablar del mundo que conocemos, ¿debemos admitir que son también parte de su ontología? Una respuesta afirmativa y, por tanto, realista, ofrece una explicación directa de los fenómenos de predicación y clasificación que nuestro lenguaje exige para poder comunicarnos y referirnos a lo real: distintos en número pueden ser también lo mismo porque comparten (instancian, participan de...) una misma entidad universal. Un canto rodado y un trozo de granito comparten una naturaleza universal común de Piedra; la Guerra, el Maltrato y la Maldad se instancian en todo aquello así llamado con verdad; y Platón, Sócrates y Aristóteles comparten la relación universal Ser-discípulo-de. Para el filósofo nominalista, sin embargo, la pregunta sobre la organización con la que se nos presenta el mundo es más complicada, pues ¿cómo explicar un mundo organizado y linguiísticamente clasificable si en la lista de lo que hay sólo se cuenta lo individual, nunca repetible ni repartible en su totalidad? Abelardo se enfrentó a esta pregunta. 
Aunque su respuesta exacta aún sigue abierta a discusión, parece al menos claro que, negando la existencia de los universales, Abelardo defendió sin embargo que el conjunto de lo individual no se agota en las substancias primeras, en las cosas, sino que incluye todos los accidentes aristotélicos, así como las diferencias, lo propio, y la mayor parte de lo que cae bajo las categorías aristotélicas. La existencia de estos individuales abstractos es la garantía final de la generalización y predicación universal que, en tanto universal, ocurre exclusivamente a nivel linguístico. Abelardo inauguró en este sentido una forma de nominalismo linguíístico en términos de status y significados comunes que se imponen desde la propia naturaleza individual de las cosas, y que, dos siglos más tarde, Ockham terminará encerrando en el lenguaje, no externo, del pensamiento.

Ahora bien, es obvio que la compleja teoría de Abelardo no es la única respuesta nominalista. Y Abelardo, al tiempo que desarrollaba su nominalismo lingüístico, realizó una evaluación crítica y sistemática de otros nominalismos más "simples", en concreto, estos tres: el mentalismo, el nominalismo de conjuntos, y el nominalismo basado en una relación básica de semejanza. Estas formas de nominalismo han resurgido de forma extraordinaria en el último siglo de desarrollo de la metafísica analítica, pero el estudio y valoración de los argumentos medievales al respecto ha sido escaso, si no nulo. Me gustaría aquí, no sólo recuperar la crítica de Abelardo para esta discusión, sino mostrar también cómo sus argumentos, además de haber sido posteriormente repetidos, aún no han podido ser superados.

\section{MENTALISMO}

La tesis general que define el nominalismo mentalista podría resumirse así: cuando clasificamos (certeramente) a muchos distintos bajo lo mismo por ejemplo, cuando decimos que este alcornoque y este ciruelo son árboles, o que todos los hombres son mortales y racionales, lo que parecen universales, las propiedades (específicas o no) de ser Alcornoque, Ciruelo, Árbol, Inteligente, Hombre, Racional, ... no son sino el pensar lo mismo de distintos individuos.

Una forma radical de mentalismo entendería los universales como imágenes mentales, a modo de dibujos o representaciones figuradas de lo que hay. Algunos empiristas británicos parecen haber defendido esta postura. Berkeley (Tratado 23), por ejemplo, en la medida en que entiende que tanto lo individual como lo universal se nos da en forma de imágenes mentales, sería un ejemplo en este sentido. Posturas mentalistas más elaboradas, como la de Ockham, defiende la reducción de lo universal, no ya a meras imágenes mentales, sino a conceptos mentales en el lenguaje del pensamiento.

Abelardo rechaza estas formas mentalistas de nominalismo. La universalidad no pertenece a las imágenes o los términos de un supuesto lenguaje del pensamiento sino que es propiedad de los términos o símbolos linguiísticos. ${ }^{1} \mathrm{Si}$ lo universal se agotase en lo mental, no podría explicarse

1 Esto no significa que Aberlardo fuese nominalista de nombres, aunque su teoría evoluciona desde el vocalismo. Los universales no son reducibles a voces, si entendemos éstas como sonidos arbitrarios. El nominalismo de nombres se atribuye normalmente a Roscelín (pero veáse Mews (1992)) de quien Abelardo fue tanto discípulo como, posteriormente, enemigo dialéctico. No obstante, han sido las palabras críticas de San Anselmo las que han venido definiendo este nominalismo: «Y puesto que hay que advertir a todos que traten con gran precaución las cuestiones de las Sagradas Escrituras, se debe excluir enteramente de la discusión de cuestiones espirituales a estos dialécticos de nuestro tiempo, o más bien a estas gentes dialécticamente herejes, que piensan que las substancias universales no son más que un soplo de la voz (flatum vocis), y que no pueden comprender que el color sea otra cosa distinta del cuerpo, o la sabiduría de un hombre distinta del alma.» (Anselmo, Carta sobre la encarnación 695). El nominalismo lingüístico de Abelardo mantiene que los términos universales significan un status universal, una especie de concepto o significado común que se impone o institucionaliza en función de la naturaleza individual de las entidades de las que el término se predica con verdad. Su nominalismo dista mucho, por tanto, de entender los términos universales como meros sonidos arbitrarios. 
el vínculo que debe existir entre lo real y lo dicho (universalmente) de lo real, cuando lo dicho es en algún sentido correcto o comprendido. Es claro, afirma Abelardo (Dialéctica 69), que las palabras en el lenguaje público causan comprensión en el intelecto. ${ }^{2}$ Pero esto sólo puede ser el caso si tienen ya significado en un lenguaje compartido. Sólo si los términos universales son previamente significantes en un lenguaje público, pueden ser causa de comprensión en el intelecto. La universalidad, por tanto, ha de pertenecer primeramente al lenguaje público y externo, si ha de ser posible comprender lo que los términos universales significan. Lo universal es causa de intelección, pero no se reduce a lo mental ni se encuentra en el pensamiento.

Como también argumentará Ockham, Abelardo defiende que las ideas en el intelecto no son imágenes mentales. ${ }^{3}$ Una idea es, más bien, un acto del entendimiento o un acto de comprensión. La comprensión se realiza desde, o mediante, las imágenes que han sido creadas por la imaginación que, a su vez, habrá necesitado de la mediación de los sentidos. Pero la idea no es una imagen mental, sino el darse cuenta, el pensar o comprender una naturaleza o una propiedad, aún cuando la imagen ha desparecido o cuando sólo nos es dada la palabra. La compresión no es la construcción de una imagen mental. De hecho, distintas personas, imaginando cosas diversas, pueden comprender lo mismo. Pero, según Aberlardo, no sólo lo universal no es una imagen que se piensa de muchos (con Ockham), sino que (y contra Ockham) tampoco es un acto de compresión. Los términos lingüísticos universales «significan» o causan actos de compresión, pero estos últimos no son lo universal. Veamos cómo escribe Abelardo sobre las imágenes y cómo se aplica su razonamiento también a los conceptos metales:

Por tanto admitimos que nada en absoluto es una imagen de este tipo ni ninguna copia de las cosas que la razón hace por sí misma para contemplar en ella algo que está ausente. Porque cuando la cosa está presente y es sentida, no necesitamos una imagen, sino que la misma realidad de la cosa se siente y se piensa sin que ninguna imagen intervenga. Ciertamente la imagen fue concebida sólo como substituto de la cosa. Pero cuando se tiene la cosa, no hay función para la copia.

Unde nil penitus esse concedimos huiusmodi imagines vel simulacra rerum, quas sibi animus fingit, ut in eis res absentes contemplari queat. Nam dum res praesens est, quae attractatur sensu, imagine non egemus, sed ipsa rei veritas et sensu et cogitatione percipitur nulla intercedente imagine. Quippe similitudo non nisi pro re concepta erat. Ubi vero res tenetur, non est opus similitudine. (Logica Ingredientibus 315: 12-17).

La razón puede "mirar" imágenes para recordar lo ausente, pero esto no significa que la naturaleza de lo ausente sea o esté en su imagen. Esto lo demuestra el hecho de que cuando algo está presente, comprendemos su naturaleza sin necesidad de atender a su imagen. Las imágenes pueden ser una ayuda ipueden incluso ser un impedimento! para la compresión de la naturaleza de las cosas, pero en ningún caso son la naturaleza de las cosas.

En la Logica Nostrorum (512:7 - 524:31) Abelardo mantiene que si accedemos y comprendemos en algún sentido la naturaleza de las cosas es porque hay una naturaleza independiente del ejercicio de nuestra imaginación y de nuestro entendimiento. La naturaleza de lo que hay, aunque pueda ser y sea comprendida por el entendimiento, es independiente del ejercicio de nuestra imaginación y de nuestro pensamiento. He aquí algunos pasajes que pueden apoyar esta idea:

Así, decimos que ciertas palabras (sermones) son universales, porque están en posición de ser predicados de muchas cosas desde su nacimiento, i.e., desde su institución por los seres humanos.

2 Sigo en esta idea de causación de la comprensión la interpretación de Gracia (1987: 289-90) y Marenbon (1997: 182).

3 Sólo en sus escritos más tempranos mantuvo Abelardo que las ideas en la mente son imágenes mentales o representaciones más o menos borrosas de individuos en el mundo. Que las ideas son conceptos mentales queda ya establecido desde la Dialectica (562: 25). 
Sic ergo sermones universales esse dicimus, cum ex nativitate, id est ex hominum institutione, praedicari de pluribus habeant. (Logica Nostrorum 522: 28-30)

Cuando digo 'Un género o una especie existe', no atribuyo nada con ello, sino que indico la institución que ya ha sido hecha, como está dicho arriba.

Cum enim dico: genus vel species est, ipsis nihil attribuo, sed institutionem iam factam, ut superius dictum est, ostendo. (Logica Nostrorum 524: 22-24)

Ciertos géneros y especies (...) están en posición de llamar (appellare) o nombrar (nominare) cosas sensibles, y (...) están en posición de significar cosas y no mediante ninguna forma sujeta a lo sensible.

Genera et species quaedam (...) sensibilia habent appellare vel nominare, et (...) res habent significare et non cum aliqua forma quae sensui subiaceat. (Logica Nostrorum 527: 23-29).

Estos pasajes, cuya interpretación podría ser clave para determinar la postura de Abelardo sobre la capacidad de predicación universal de los términos (universales) parecen dejar claro al menos que, en la predicación universal verdadera, la universalidad de los términos no puede depender de la acción de la imaginación o del pensamiento sino que estos términos poseen una significación (un sentido) previa a la compresión mental. Abelardo insiste en que la significación universal de los términos (universales) se debe a la institución pública, por tanto por parte de la comunidad de hablantes. En todo caso, queda claro que Abelardo afirma que la objetividad de la semántica es independiente de la compresión mental de cada palabra.

Este razonamiento de Abelardo recuerda de forma importante al siguiente argumento de Armstrong contra el nominalismo conceptual o mental:

Parece claro que la blancura de una cosa blanca es independiente de la existencia del concepto de blancura en las mentes de los hombres. Hay algo sobre las cosas blancas que hace que el concepto de blancura les sea aplicable. El nominalismo conceptual no da explicación alguna de este algo. (Armstrong, 1988: 58).

Es decir, a menos que neguemos la realidad de un mundo independiente de nuestro conocer, lo universal y común que afirmamos de lo que hay no puede ser mero producto de la imaginación, ni tener a la mente como condición de posibilidad. Esta misma reflexión ayuda también a comprender por qué Abelardo no puede aceptar el nominalismo de nombres. Todo filósofo que acepte la existencia de un mundo real cognoscible entiende que, aún sin voces o palabras en un lenguaje, las entidades reales se parecerían o serían lo mismo en algún sentido. ${ }^{4} \mathrm{Y}$ ya en las primeras partes de la Logica Ingredientibus Abelardo se plantea la pregunta por la causa de imposición de los nombres universales de la siguiente forma:

Está aquélla [pregunta] por la causa común de la imposición de los nombres universales, esto es, conforme a qué diferentes cosas coinciden.

[E]st illa de communi causa impositionis universalium nominum, secundum quod scilicet res diversae conveniunt. (Logica Ingredientibus 8: 12-14).

4 Parece que el joven Abelardo, siguiendo a Roscelin, había aceptado una interpretación in voce de las categorías lógicas Aristotélicas. Según esta interpretación, las categorías son voces clasificatorias; y el vínculo, si lo hay, entre ellas y lo clasificado por ellas (el mundo y sus objetos), no interesa al lógico o al gramático. Pero, aun si éste fue el caso, Abelardo cambió esta forma de entender la lógica y su relación con aquello a lo que estructura. Marenbon (1997: 26) argumenta que 'palabra' no es una traducción exacta de 'vox' ni siquiera en el uso que le da Abelardo en la Logica Ingredientibus (16: 21-2). Los gramáticos del siglo XII utilizaron 'voces' para referir a sonidos producidos por animales o personas. Las voces podían tener o no significado, $\mathrm{y}$, de tenerlo, podía ser o no por imposición (voces significativae ad placitum). Como hemos visto, que las voces son significantes por imposición o institución es definitivamente la postura de Abelardo en la Logica Nostrorum, cuando escribe que los universales son sermo. 
Esta pregunta, aunque claramente enmarcada en el ámbito del lenguaje y la predicación, no se limita al ámbito de la gramática, sino que apunta al vínculo entre los nombres universales y aquello de lo que con verdad se dicen, o en virtud de lo cuál se imponen. Y es que, al tiempo que se defiende una ontología exclusiva de individuales, el nominalista debe dar cuenta del vínculo entre el nombre (universal) y lo real. Pero ni el nominalismo de palabras, ni el mentalista (de ideas o conceptos) cumplen con esta labor. No hay que confundir, por tanto, el nominalismo (postura contraria al realismo de universales) con posturas contrarias al realismo cognoscitivo. La primera dicotomía concierne a la ontología; la segunda a la epistemología. El nominalismo es una postura ontológica y, por ello, un realista epistemológico, como lo fue Abelardo, que afirma que nuestro conocimiento lo es efectivamente de lo que hay, puede negar la existencia de universales al tiempo que acusa a su contrario epistémico de no hacer pie en el suelo de la realidad.

\section{NOMINALISMO DE CONJUNTOS Y COLECCIONES}

El nominalismo de conjuntos o colecciones defiende que cuando clasificamos o cuando predicamos con verdad lo mismo de muchos distintos, lo que creemos universal es, más bien, una colección o un conjunto natural de individuos. La Tristeza, por ejemplo, no es sino el conjunto de las cosas tristes; Árbol, el conjunto de todas las que son árboles; Ser-padre-de, el conjunto de todas las que se encuentran en dicha relación. Las cosas que están tristes, son árboles, o son padres coinciden naturalmente en esto: que son árboles o padres o están tristes. Este "coincidir en" no significa que compartan, instancien o participen de, una misma propiedad o relación universal: no hay propiedades, ni relaciones; no hay universales. Es simplemente un hecho básico e inanalizable, algo que forma parte del propio modo de ser de lo que hay, que en el mundo hay árboles, padres y entes que se entristecen.

Por tanto, las substancias, los objetos, tal y como son, agotan la ontología de lo real. Más aún, tampoco importa mucho cuáles puedan ser los objetos últimos del mundo: mesas, ríos, átomos, o neutrinos son todos en principio candidatos igualmente válidos aunque, como en el caso de Quine (1969), suele adoptarse cierto naturalismo científico según el cuál las ciencias, en su quehacer, irán determinando estas entidades últimas. La tesis fundamental, en todo caso, es que lo que hay se reduce al mundo de las sustancias primeras. Éstas son lo que son y como son, y desde este ser suyo total e indivisible conforman conjuntos de forma natural. Quine es contundente al respecto:

Las palabras 'casa', 'rosa' y 'crepúsculo' son verdaderas de numerosas entidades individuales que son casas rojas, rosas rojas o crepúsculos rojos; pero no hay además de eso ninguna entidad, individual o no, denominada por la palabra 'rojez', ni, por lo demás, entidades denominadas 'caseidad', 'roseidad', 'crepusculeidad'. El que las casas, las rosas y los crepúsculos sean todos ellos rojos puede ser considerado hecho último e irreducible... (Quine, 1953: 36).

Tal vez la escuela de Joscelín de Soissons defendió esta idea de universalidad, pero véase Thompson (1995). Sea como sea, Abelardo sí ponderó y criticó la idea de que lo universal pueda entenderse como una colección de individuos. ${ }^{5}$ Dos de sus argumentos que, sin mención a Abelardo, aún se consideran hoy día, parecen incontestables. Veámoslos.

5 El nominalismo de colecciones que Abelardo critica no se corresponde de forma absoluta con el nominalismo de conjuntos de Quine. Por ejemplo, Quine, pero no Abelardo, consideraría el conjunto vacío como un universal: hay conjuntos sin elementos, pero no hay colecciones sin ellos. El desarrollo de la teoría de conjuntos matemática impide, por tanto, que hoy día podamos identificar conjuntos y colecciones. Los conjuntos son entidades matemáticas bien definidas desde propiedades y principios aceptados. Las colecciones, sin embargo, no han adquirido nuevo sentido filosófico. Pero esto, como se verá, no es óbice para que las críticas de Abelardo contra el nominalismo de colecciones sean igualmente válidas cóntra el nominalismo de conjuntos. 
El primero puede enunciarse así: los universales no pueden explicarse en términos de colecciones (ni de conjuntos) de individuos, porque las colecciones no se dicen de sus partes (ni los conjuntos de sus miembros) al modo en que los universales se dicen de muchos:

[P]reguntemos cómo toda la colección de hombres que se denomina una especie, puede predicarse de muchos, de tal modo que sea un universal (...). Si se aceptara que se predica de diferentes cosas mediante sus partes en tanto que sus partes individuales le son adecuadas, nada hay en ello de la comunidad del universal, que según Boecio debe estar como un todo en los singulares, diferente de lo que es común a través de sus partes al modo de un campo cuyas diferentes partes son diferentes.

[Q]uomodo tota simul hominum collectio quae una dicitur species, de pluribus praedicari habeat, ut universalis sit, perquiramus (...). Quod si per partes de diversis singulae eius partes sibi ipsis aptentur, nihil ad communitatem universalis, quod totum in singulis teste Boethio esse debet atque in hoc ab illo communi dividitur quod per partes commune est, sicut ager cuius diversae partes sun diversorum. (Logica Ingredientibus 14: 33-40).

Una colección (un conjunto) es común a sus partes al modo en que lo es un campo que, componiéndose de partes, es común a todas ellas. Cualquier parte del campo es campo en tanto el propio campo se extiende en ella. Pero el universal no se extiende en sus ejemplares como el campo en sus partes. El universal no es suma ni resultado de sus ejemplares, sino que es común como un todo, no repartido ni distribuido. Rojo, por ejemplo, no se extiende en las cosas rojas al modo en que el campo lo hace en sus partes. Rojo se dice, como un todo, de cada una de las cosas rojas. Y cada cosa roja no es parte del universal Rojo, pues en tal caso, que algo fuese rojo dependería de la existencia de otras cosas rojas, al igual que el que algo sea parte de un campo depende de la existencia de otras partes que lo forman. Pero esto, obviamente, no es el caso: que un atardecer sea rojo no está, de ninguna forma, en función de que otras entidades puedan ser también rojas. Los universales, por tanto, no son meras sumas, conjuntos, o colecciones.

Un segundo argumento dice así:

Todo universal es naturalmente previo a sus propios individuos. Pero una colección se relaciona con los individuos de los que está compuesta como un todo íntegro y es naturalmente posterior a ellos.

Omne universale propriis individuis naturaliter prius. Collectio vero quorumlibet ad singula quibus constituitur, totum integrum atque eis naturaliter posterius, ex quibus componitur. (Logica Ingredientibus 15: 15-18).

Podemos llamar a este segundo argumento el argumento de la dependencia ontológica, y resumirlo como sigue. El universal es primero a sus ejemplares en el sentido de que no depende de ellos para ser, ni cambia en función de su número. Cuando Sócrates muere, no hay ningún sentido en el que Hombre o Humanidad cambien. La muerte o el nacimiento de Sócrates no afecta a lo universal. Esto significa que un universal no está determinado por los individuos de los que se dice con verdad. Sin embargo, una colección sí depende ontológicamente de sus partes: todas y cada una de ellas le son esenciales. La colección de todos los hombres es otra cuando sus elementos cambian y está incompleta si alguno falta. Al desaparecer Sócrates, la colección de los hombres cambia, pero el Hombre no, pues tanto a los conjuntos como a las colecciones sus miembros les pertenecen de modo esencial, pero la naturaleza del universal no depende en modo alguno de sus ejemplares. ${ }^{6}$

6 Es ley en teoría de conjuntos que $x$ e $y$ son el mismo conjunto si y sólo si $x$ e $y$ tienen los mismos miembros. Es decir, un cambio en los miembros de un conjunto, automáticamente convierte dicho conjunto en otro conjunto distinto. 
Este argumento tiene un corolario importante: si los universales fuesen conjuntos o colecciones, todas las propiedades serían esenciales a sus individuos. Las propiedades, entendidas como colecciones o conjuntos, exigirían todos sus miembros, pues de otro modo, no serían las mismas propiedades. Pero esta consecuencia es a todas vistas inaceptable: es claro que los mismos (al menos, algunos) individuos podrían no haber tenido las (al menos, algunas) propiedades que de hecho tienen, y que además podrían haber tenido otras propiedades. Es decir, los mismos (o algunos) universales podrían haber sido instanciados por otros individuos, y los mismos (o algunos) individuos podrían haber instanciado otros universales.

En suma, la primera crítica de Abelardo al nominalismo de colecciones resalta el carácter de agregado de las mismas. Las colecciones se encuentran en la relación parte-todo con sus partes, desde la relación de suma que se da entre dichas partes. Sólo en este sentido las colecciones son comunes a sus partes, distribuyéndose en ellas. Los universales, por contra, no se encuentran en la relación parte-todo con los individuos que los instancian, ni son en el mismo sentido comunes a ellos, sino que se encuentran, como uno, en todos y cada uno de sus individuos. Por otra parte, la segunda crítica señala la inaceptable dependencia ontológica del universal respecto de sus ejemplares. Ambas críticas siguen vigentes. ${ }^{7}$

No obstante, también se viene discutiendo una posible salida a estas dificultades, siguiendo la metafísica de mundos posibles de David Lewis. Asumamos una ontología de individuos posibles, contrapartes de los individuos actuales, que viven en mundos posibles. Estos mundos posibles son lo que comúnmente entendemos por situaciones posibles: mundos en los que ocurre lo que podría ocurrir o haber ocurrido en nuestro mundo en acto o actual. Admitamos ahora individuos posibles entre los elementos de los conjuntos o colecciones que son los universales. Por ejemplo, el Hombre, como especie, sería en realidad el conjunto de todos los individuos, posibles y actuales, que son hombres; el Burro el conjunto de todos los burros, actuales y posibles ... y así con todo lo universal. Con esto, solucionamos el problema de la esencialidad de los miembros:

Es un error decir que si una propiedad fuese un conjunto, entonces tendría sus instancias sus miembros esencialmente, y por tanto que nunca sería contingente que algo la tenga o la carezca. Considérese la propiedad de ser un burro parlante, que digo es el conjunto de todos los burros parlantes entre todos los mundos. Los miembros de este conjunto no varían de mundo a mundo. Lo que varía es el subconjunto que conseguimos si nos ceñimos a nuestro mundo en cuestión. Así es cómo el número de instancias es contingente; por ejemplo es contingentemente cierto que la propiedad no tiene instancias. Más aún es contingente si algún individuo particular tiene la propiedad o no. Cojamos a Brownie, un burro parlante de otro mundo. Brownie mismo es, de una vez y para siempre, un miembro del conjunto; por tanto, de una vez y para siempre, una instancia de la propiedad. Pero es contingente que Brownie pertenezca al conjunto: Brownie tiene contrapartes que pertenecen y contrapartes que no. Así es como es contingente que Brownie tenga la propiedad. (Lewis, 1986: 50-1).

Aceptando contrapartes o mundos de possibilia, la pertenencia esencial a los conjuntos pasa a un segundo plano y se restablece la distinción entre propiedades contingentes y necesarias. Que algo tenga una propiedad esencialmente significa ahora que todas sus contrapartes, i.e., todos los individuos posibles que ese algo podría haber sido, tienen también esa propiedad. Y que algo tenga una propiedad contingentemente significa que al menos una de sus contrapartes no tiene dicha propiedad. Es factible, por tanto, en entender las propiedades como conjuntos o colecciones. Sigue siendo el caso que todos/as tienen sus miembros de forma esencial, pero ahora podemos distinguir entre conjuntos: los conjuntos que incluyen todos indivi- 
duos, posibles y actuales, que poseen la propiedades, y los subconjuntos de estos restringidos a cada mundo. Los primeros son el universal, pero los segundos permiten distinguir la esencialidad o contingencia de la propiedad en cuestión. El realismo de mundos posibles y possibilia parece solucionar, por tanto, la segunda dificultad planteada por Abelardo, al tiempo que explica al más puro estilo nominalista todas la propiedades en términos de conjuntos. ${ }^{8}$

No obstante, el precio a pagar por esta solución es alto. En primer lugar, seres meramente posibles habrían de ser admitidos en la ontología de lo real, lo que resulta, cuando menos, contraintuitivo. Pero, además, se resucita la primera crítica de Abelardo, puesto que al reducir las propiedades a conjuntos de ejemplares, actuales y posibles, aún entendemos las propiedades, y su esencialidad o contingencia, relacionalmente. Es decir, si las propiedades son conjuntos de entidades (actuales o no), que un individuo sea tal cual es depende de la existencia y naturaleza de otros seres. Por ejemplo, que sea cierto que yo pudiese haber sido mejor persona, significa que existe al menos un individuo posible (que además es contraparte mía) que es bastante mejor en su mundo que yo en el mío. Pero que yo pudiese haber sido mejor persona no puede depender de la existencia y bondad de este otro posible ser. Abelardo, según parece, aún tiene la última palabra.

\section{NOMINALISMO DE SEMEJANZAS}

El nominalismo de semejanzas es una prolongación casi obligada del nominalismo de conjuntos. Se trata de explicar la naturalidad con la que supuestamente los individuos se agrupan en conjuntos, en términos de una relación básica de semejanza entre los elementos del conjunto, dotándolo así de mayor cohesión o estructura. El universal se identifica entonces con un conjunto de entidades semejantes entre sí. En general, se acepta que la relación de semejanza es objetiva. Además, y aunque la semejanza se da de hecho en grados (de forma que cada cosa se parece a muchas otras en grados incontables), se supone que es el mayor grado de semejanza, es decir, el grado de semejanza exacta, el que explica lo universal. La relación de semejanza exacta da lugar a conjuntos de entidades que se parecen exactamente entre sí (o a algún elemento paradigmático dentro del conjunto), ${ }^{9}$ y no hay ninguna entidad fuera del conjunto a la que todos se parecen. Así, la Tristeza, por ejemplo, es el conjunto de lo que se asemeja entre sí (o a un paradigma de lo triste, como La Dolorosa o Boabdil) más de lo que los individuos que así forman el conjunto de lo triste se parecen a elementos externos.

Decía que el nominalismo de semejanzas es una prolongación casi obligada del nominalismo de conjuntos porque evoluciona, entre otras razones, para dar respuesta a un problema obvio con el que se enfrenta su contrapartida (sin posibilia). El problema es el siguiente. Sabemos que dos conjuntos (o colecciones) son idénticos si y sólo si tienen los mismos miembros. Pero considérese cualquier bicondicional verdadero universalmente cuantificado: por ejemplo, el clásico medieval, 'todos, y sólo, los seres humanos pueden reír', o el ejemplo de Quine, más contemporáneo, 'todas, y sólo, las criaturas con riñón son criaturas con corazón'. Si las propiedades universales fuesen el conjunto de sus extensiones o ejemplares, esto significaría que las propiedades ser capaz de reir y ser humano son la misma propiedad, puesto que el conjunto de las criaturas que ríen y el conjunto de los humanos es el mismo. Por lo mismo, las propiedades tener corazón y tener riñón habrían de ser las mismas, puesto que las críaturas que tienen corazón y las que tienen riñón coinciden. Es obvio, sin embargo, que las propiedades son otras.

8 Tampoco la idea de incluir individuos posibles en los conjuntos es nueva. Por ejemplo, a pesar de que Ockham negó también el nominalismo de conjuntos y defendió una versión mentalista de nominalismo, incluyó possibilia en la extensión de los términos universales pues afirma que, en un segundo sentido de significación, 'blanco' por ejemplo, «no sólo significa lo que ahora es blanco sino también lo que puede ser blanco.» (Summa Logicae I, c. 33; $O P I$, p. 95$)$.

9 Price (1953: 32-4) utiliza paradigmas como base de la relación. 
¿Soluciona el nominalismo de semejanzas esta dificultad? Parecería que no. Por ejemplo, todas las criaturas que se parecen entre sí en tanto que tienen la capacidad de reír y forman, en este sentido, el conjunto de las criaturas que ríen, forman igualmente el conjunto de las criaturas que son humanas aunque este conjunto se forme desde su semejanza en tanto son humanas. Ambos conjuntos, por tanto, son de hecho el mismo. ${ }^{10}$ Sin embargo, una forma más desarrollada de nominalismo de semejanzas, el nominalismo de abstractos individuales y semejanzas, sí ofrece solución a este problema. Según esta forma de nominalismo, los elementos de los conjuntos formados por semejanza no son ya individuos concretos o sustancias, sino propiedades o relaciones individuales, últimamente denominados «tropos». Por ejemplo, John Bacon, escribe:

Intuitivamente, un tropo [un individual abstracto] es una propiedad "fina", e.g. la rojez de Mao en contraste con la rojez como tal. La última puede entonces entenderse como el conjunto de todas las rojeces particulares, y lo mismo para otras propiedades genéricas. Los rojos particulares son exactamente similares entre sí en tanto son rojos, casos de la misma cualidad. (...) [La semejanza] da lugar a clases de semejanza, cuyos elementos son todos similares entre sí y no todos similares a otro distinto. (Bacon, 1989: 141)

La teoría de tropos explica (...) las propiedades o relaciones en términos de montones de tropos. Un montón es una clase de semejanza, un conjunto maximal de tropos todos similares entre sí. Es maximal en que nada que sea similar a todos los miembros queda fuera del conjunto. (Bacon, 1995: 13).

La dificultad anterior se resuelve, por tanto, si los elementos de los conjuntos a los que reduciremos el universal, no son sustancias, sino abstractos individuales. Es decir, los elementos de los conjuntos son propiedades o relaciones individuales, como el color individual exacto de esta hoja de papel, o la forma individual de este carácter ortográfico. Siendo así, el conjunto formado (por semejanza) por todas las humanidades individuales y el conjunto formado (por semejanza) por todas las particulares capacidades de reír, contienen elementos distintos. Son, consecuentemente, dos conjuntos diferentes. Igualmente, el conjunto formado (por semejanza) por todas las propiedades individuales de tener-riñón es diferente del conjunto formado (por semejanza) por las propiedades individuales de tener-corazón.

El nominalismo que pretende explicar lo universal desde la semejanza de abstractos individuales es la forma de nominalismo más desarrollada hoy día, v.g. Bacon (1995), Campbell (2002), Maurin (2002)). Por eso la crítica de Abelardo se hace aquí especialmente interesante: siendo él mismo defensor de los abstractos individuales, Abelardo rechazó esta forma de nominalismo con argumentos contundentes.

En primer lugar, si aceptamos que lo universal no es sino el conjunto formado por la semejanza entre individuos, también la propia relación de semejanza habrá de ser un conjunto formado por individuos: en concreto, los individuales abstractos que son todas las relaciones de semejanza individuales. Pero nos enfrentamos entonces, y a decir de Abelardo, a un regreso al infinito: cada relación individual de semejanza se asemejará a otra relación individual de semejanza por otras relaciones individuales de semejanza que, a su vez, habrán de asemejarse entre sí por nuevas relaciones de semejanza, y así ad infinitum. La conclusión de Abelardo será que no puede haber relaciones individuales de semejanza; su existencia sólo está en nosotros mismos:

Pues también en nosotros muchas cosas se consideran relativamente, aunque nadie en su sano juicio aceptaría que las propias relaciones fuesen algo distinto de nosotros. Efecti-

10 Naturalmente, un realismo de mundos e individuos posibles solucionaría este problema sin mayor dificultad: simplemente presuponiendo mundos donde viven criaturas con riñón y sin corazón (y al contrario), o mundos con humanos que no ríen y mundos con seres risueños pero que no son humanos. 
vamente cada cosa se dice semejante a cualquier otra en aquello que tiene como ser, o bien opuesta o diferente en aquello que ella misma no es. Pero si la semejanza o la oposición fuese esencialmente distinta de aquella cosa de la que se dice que es relación, en tanto que la misma semejanza fuese semejanza y la misma oposición opuesta, ¿quién podría evitar racionalmente el supremo inconveniente de la infinitud ...?

Nam et in nobis ipsis multa relatiue accipiuntur, cum nemo discretus relationes ipsas aliud a nobis esse concedat. Quippe unaquaeque res cuilibet alteri similis dicitur in eo quod esse habet, uel etiam opposita siue dissimilis in eo quod non est ipsa. Quod si similitudo uel oppositio $a b$ ea re, cuius relatio dicitur, diuersa essentialiter sit, cum ipsa rursus similitudo similis sit et ipsa oppositio opposita, quis summum infinitatis inconueniens uitare rationabiliter poterit ...? (Theologia Christiana 259: 2109-15).

Según Abelardo, no hay semejanza real en el mundo, pues ninguna relación de semejanza puede ser algo independiente ni distinto de lo que relaciona. Si lo fuera, cada semejanza individual se asemejaría a otra semejanza individual, y así infinitamente, como ya hemos visto. Abelardo se adelanta así a uno de los argumentos más importantes contra la versión más contemporánea de nominalismo, es decir, aquélla que incluye abstractos individuales en su ontología y utiliza relaciones básicas de semejanza para explicar la predicación y reducir lo universal. ${ }^{11}$

Pero Abelardo presenta aún un segundo argumento incontestable, o al menos incontestado hasta hoy día, contra la relación de semejanza. Según este razonamiento, pensar que la semejanza (o cualquier otra relación individual o universal) pueda tener identidad propia nos lleva al siguiente absurdo:

¿Qué podría ser más ridículo que suponer que cuando alguien a quien me asemejo nace, algo nuevo debiese aparecer en mí que, cuando él perezca, se destruirá necesariamente?

Quid enim ridiculosius ut, cum aliquis modo nascitur cui similis efficior, propter illum quaedam res noua mihi innascatur quam cum ille perierit necesse sit deperire? (Theologia Christiana 259: 2119-22).

Es irracional creer que algo, una relación (individual) de semejanza, surge o se destruye en una sustancia dada cuando otra sustancia, a la que la primera se asemeja, aparece o muere. La semejanza, por tanto, no puede ser algo más que las sustancias relacionadas y la conclusión final de Abelardo es, otra vez, que tal relación sólo existe en nuestro intelecto. Este argumento es aplicable directamente contra el nominalismo de conjuntos de abstractos individuales cohesionados por relaciones individuales de semejanza. Pero el argumento es igualmente eficaz contra la forma realismo aristotélico defendida por Armstrong (1978) según el cual, los universales están defectivamente en todas las substancias que los instancian. Según esta teoría, la

11 Russell, a principios del s. XX y en su defensa del realismo de universales, presentó un argumento parecido, aunque menos complejo que el de Abelardo, al considerar que los elementos de los conjuntos que los universales son únicamente objetos o substancias, y no ya propiedades o relaciones individuales. Russell argumentó que, si lo que parece un universal no es sino un conjunto de entidades concretas semejantes, la semejanza misma habrá de explicarse desde conjuntos de individuos que entran en nuevas relaciones de semejanza, y así sin fin: «[E]xplicamos el parecido de dos términos como consistiendo en el parecido que su parecido tiene con el parecido de otros dos, y este regreso está claramente viciado.» (Russell, 1912: 172). Me gustaría también señalar que, contrariamente a lo que pueda parecer, el argumento de Abelardo no es el argumento de tercer hombre de Platón. El regreso de Platón, aplicado a relaciones o propiedades individuales se genera de la siguiente forma. Consideremos dos abstractos individuales cualesquiera $a$ y $b$. Si $a$ y $b$ están relacionados por una relación individual $r$, entonces ha de haber otra que sirva de unión entre los tres, pongamos $r_{1}$. Pero para ello es otra vez necesario que $a, b, r$ y $r_{1}$ estén relacionados por otra relación individual $r_{2}$, y así, sin fin. El regreso de Platón hace depender las nuevas relaciones que se generan sin fin de las relaciones previas que dependen, a su vez, de las nuevas. El regreso de Abelardo (y de Russell) simplemente genera nuevas relaciones ad infinitum. 
Semejanza como universal existe en todas las substancias que la instancian. Pero, entonces, cada vez que desaparece (o aparece) una de las substancias en las que la Semejanza inhiere, la propia Semejanza ha de destruirse (o crearse). Y esto es, claramente, absurdo. ${ }^{12}$

\section{CONCLUSIONES}

Mi intención en este trabajo no ha sido presentar o defender la forma de nominalismo que Abelardo propuso. No obstante, sí he apuntado durante la discusión que Abelardo pudo haber defendido que los términos universales, además de múltiple referencia, adquieren por imposición o institución pública un significado o sentido linguiístico previo a la compresión mental que ellos mismos causan. Sin embargo, mi objeto se ha centrado fundamentalmente en mostrar cómo ciertas formas contemporáneas de nominalismo, más simples que la del propio Abelardo, fueron ya cuidadosamente sopesadas y críticamente evaluadas por él. Más aún, Abelardo no sólo ofreció argumentos importantes en contra del mentalismo, el nominalismo de conjuntos o el de semejanzas, que se han repetido siglos después casi textualmente, sino que algunos de estos argumentos superan en complejidad a sus contrapartes actuales, siendo muchos además aún hoy por hoy incontestables. ${ }^{13}$

\section{REFERENCIAS}

Abelardo, P. Dialectica L. M. de Rijk (ed.) Petrus Abelardus Dialectica, Van Gorcum, 1956.

- Logica Ingredientibus B. Geyer (ed.) Peter Abaelard's Philosophische Schriften, Aschendorff, 1919-33.

- Logica Nostrorum B. Geyer (ed.) Peter Abaelard's Philosophische Schriften, Aschendorff, 1919-33.

- Theologia Christiana E.M. Buytaert (ed.), Turnhoult, 1969.

Anselmo (1094) Carta sobre la encarnación del Verbo (La fe en los Misterios de la Trinidad), En Obras completas de San Anselmo vol. I B.A.C., 1952.

Armstrong, D. M. (1978) Los universales y el realismo científico, UNAM, 1988.

Bacon, J. (1989) A Single Primitive Trope Relation, en Journal of Philosophical Logic 18: 141-54.

- (1995) Universals and Property Instances: The Alphabet of Being Blackwell.

Berkeley, G. (1710) Tratado sobre los principios del conocimiento humano, Losada, 1939.

Campbell K. (1990) Abstract Particulars, Balckwell.

- (2002) Unit Properties, Relations, and Spatio-temporal Naturalism en The Modren Schoolman 79(2-3): $151-162$.

Gracia, J. J. E. (1984) Introducción al problema de la individuación en la alta Edad Media, UNAM, 1987.

Lewis, D. K. (1986) On the Plurality of Worlds, Blackwell.

Loux, M. (1998) Metaphysics: a Contemporary Introduction, Routledge.

Marenbon, J. (1997) The Philosophy of Peter Abelard, Cambridge University Press.

Maurin, A. (2002) If Tropes, Kluwer.

Mews, C.J. (1992) Nominalism and Theology before Abaelard: New Light on Roscelin of Compiègne en Vivarium 30:5-33.

Moreland, J.P. (1985) Universals, Qualities, and Quality Instances, University Press of America.

12 Ockham utilizará este mismo argumento en una crítica generalizada contra los universales (Questiones 163, 1.13-164, 1.9) y, hasta dónde he sido capaz de saber, nadie ha ofrecido aún respuesta a este problema.

13 Este trabajo ha sido realizado dentro del programa de investigación 'Ramón y Cajal' que avala el Ministerio de Ciencia y Tecnología en España. Vaya mi agradecimiento para Remedios Ávila, María J. Frápolli, Víctor Morla, y Francisco Tornay por sus comentarios, sugerencias, y su ayuda con los textos en latín. 
Ockham, W. Questiones in libros sententiarum En su Opera Theologica vol VII Iuvernalis Lalor (ed.) St Bonaventure University Press, 1967-86.

- Summa logicae I En su Opera Philosophica vol I, St Bonaventure University, 1967-88.

Price, H.H. (1953) Universals and Resemblance. Chapter I of Thinking and Experience. En van Inwagen \& Zimmerman (eds.) Metaphysics: The Big Questions Blackwell, 1998, pp. 23-40.

Quine, W. (1953) Acerca de lo que hay. En su Desde un punto de vista lógico Orbis, 1984, pp. 24-47.

- (1969) Natural Kinds. En Rescher (ed.) Essays in Honor of Carl G. Hempel Routledge, 1969, pp. 5-23.

Russell, B. (1912) On the Relations of Universals and Particulars. En sus Logical and Philosophical Papers 1909-13 Routledge, pp. 167-182.

Thompson, A. (1995) The Debate on Universals before Peter Abelard Journal of the History of Philosophy 33(3): 409-429.

M. J. García-Encinas

E-mail: mjgencinas@yahoo.com 